\title{
APROXIMACIONES Y DISTINCIONES ENTRE LA DIDÁCTICA DE LA LECTURA Y LA DIDÁCTICA DE LA LITERATURA
}

Ximena Azúa 


\section{XIMENA AZÚA}

Licenciada en Lengua y Literatura Hispánicas, Magíster en Estudios Latinoamericanos y Doctora en Literatura de la Universidad de Chile. Académica de la Facultad de Ciencias de la Universidad de Chile. Se desempeñó como directora del Departamento de Educación de la Facultad de Ciencias Sociales de esta misma Universidad y como coordinadora de programas tanto de investigación como de asuntos académicos. 


\section{APROXIMACIONES Y DISTINCIONES ENTRE LA DIDÁCTICA DE LA LECTURA Y LA DIDÁCTICA DE LA LITERATURA ${ }^{1}$}

Durante el verano se suscitó un debate interesante entre libreros, bibliotecarios y editores respecto de la selección y compra de libros realizadas por la Dirección de Archivos y Museos para las bibliotecas públicas. ${ }^{2}$ La selección realizada por los bibliotecarios de las distintas ciudades de nuestro país fue criticada por algunos editores y libreros por ramplona, a lo cual respondieron los aludidos indicando que esos títulos eran aquellos que los lectores solicitaban mayoritariamente y, por lo tanto, las bibliotecas públicas debían satisfacer dicha demanda.

Dicha discusión fue interesante, pues puso en juego distintas concepciones de la lectura y, por cierto, sobre la perspectiva de cómo abordarlas a través de una política pública. En efecto, los bibliotecarios estaban defendiendo las preferencias de los lectores; por su parte, editores y libreros aludían a una selección de títulos no solo más clásicos, sino que más complejos. En definitiva, una mirada de la lectura como elemento formador, y los primeros ponían al centro la lectura como un elemento de solaz. ${ }^{3}$

Ciertamente, la lectura es ambas cosas y muchas más, el punto es cómo en la formación de lectores vamos generando prácticas de fomento de aquella que den cuenta de la diversidad de estos, si se considera que la lectura es una práctica cultural que implica una interacción con el texto y múltiples intercambios sociales, que se instala desde el soporte o materialidad del texto y las capacidades intelectuales del lector (Chartier, 1998).

Las prácticas de lectura implican que el acto lector se puede realizar completa o parcialmente, de forma lineal o vertical, continua, entrecortada, discontinua, fragmentada, rápida o lentamente, e incluso, de forma oral o silenciosa. Como toda práctica, esta no es homogénea en todo lugar y espacio social, así como tampoco los lectores comparten los mismos gustos por los mismos tipos de textos.

En esta perspectiva la discusión entre bibliotecarios y algunos editores no es trivial, pues lo que indica es que unos y otros tienes distintas perspectivas de lo que es leer. Los editores, con su crítica, no solo cuestionaron los títulos seleccionados, sino que dejaron entrever que las bibliotecas públicas deben ser espacios para una determinada lectura o

1. Las ideas aquí expresadas son producto de mi reflexión a partir de las clases realizadas a profesores de lenguaje, de nivel de enseñanza media y básica, en el marco del Programa de Educación Continua, así como también a partir de la discusión permanente con mis estudiantes de postgrado en el marco del desarrollo de sus tesis. A todos ellos, muchas gracias.

2. El desarrollo de esta discusión fue publicado en los diarios de circulación nacional, tales como El Mercurio y La Tercera, entre los días 19 y 22 de febrero de 2014.

3. Jean Hebrard plantea que tempranamente los bibliotecarios entendieron que la lectura es un placer, noción que se instala mayoritariamente a inicios del siglo XX. 
tipos de textos y, por ende, parecieran considerar que los lectores son un grupo bastante homogéneo.

No es casual que los bibliotecarios, que cotidianamente se relacionan con los más variados tipos de lectores que asisten a las bibliotecas públicas, perciban la heterogeneidad de dichos lectores.

Sin embargo, la heterogeneidad de los lectores no solo tiene que ver con sus preferencias, sino también con sus formas de leer, las cuales se determinan de manera importante por el soporte material en el cual el texto está encarnado. En esa perspectiva, la disputa solo mostró una de las puntas del iceberg, pues quizás la más compleja es que hoy los lectores nacidos en la era digital leen muy poco en textos impresos y muchísimo más en la red ${ }^{4}$.

Uno de los grandes consensos que hoy existe en el ámbito educacional, intelectual, en la implementación de políticas públicas, etc., es la necesidad de incentivar la lectura o, como se dice en la actualidad, "la comprensión lectora", como si leer un texto y comprenderlo fueran cosas distintas. Leer es comprender, el punto - no trivial- de ello es el nivel de profundidad de esa lectura.

Hoy, el incentivo a la lectura genera una serie de actividades y planes para la formación de nuevos lectores 5 . Acciones vanas, todas ellas, en la medida en que no consideran dos elementos cruciales: las diversas formas de lectura que conviven en la actualidad y, en particular, la nueva práctica de la lectura digital; y, el segundo elemento, el abordaje de cómo se desarrolla la enseñanza de la literatura en las aulas.

4. A partir de la encuesta realizada por el Consejo de Cultura en el año 2011, en el Reporte de Libro y Lectura se indicaba que, respecto de la lectura de libros, un 41,4\% de los encuestados el año 2009 declaraba haber leído al menos un libro durante los últimos 12 meses, mientras que un 53,9\% declaraba no haberlo hecho, y un 4,7\% señalaba no haberlo hecho nunca por voluntad propia. Estos valores son consistentes con los datos de 2005, en los que — sin que se incluyera la alternativa "nunca ha leído un libro voluntariamente" - un 41\% había leído y un 59\% restante no lo había hecho. Consejo Nacional de la Cultura y las Artes, "Reporte Estadístico N², Libros y lectura", sección Estudios, Observatorio Cultural, Chile, 2011. Cabe señalar que no existen datos comparables respecto de la lectura impresa y digital, pero si se considera que en Chile el tiraje de libros impresos asciende generalmente a 1000 ejemplares. Sin embargo, si observamos los portales más frecuentes entre los jóvenes, los que tienen un conteo respecto de los ingresos al portal, supera con creces las 1000 visitas en el mes, o quizás más. A modo de ejemplo, el portal www.amor-yaoi.com entre los meses de mayo y septiembre del 2013 registro 62.487 visitas (Bustos, 2013).

5. El Plan de Fomento Lector actualmente vigente en nuestro país es responsabilidad de tres entidades: el Ministerio de Educación, la Dirección de Bibliotecas y Museos y el Consejo Nacional de las Cultura y las Artes, cuyo objetivo central es fomentar la práctica de la lectura y el incremento de lectores. Es un plan ambicioso en el que las tres entidades han diseñado planes de acción en distintos ámbitos, pero ciertamente hay una importante focalización en la primera infancia. El Ministerio de Educación ha diseñado planes de animación y hábito lector, pero todos ellos se promueven a partir del soporte del libro; la Dirección de Bibliotecas y Museos es la única que, en el marco del Plan, incluye plataformas digitales y capacitación sobre su uso. 
En este texto pretendo reflexionar sobre ambos elementos desde la perspectiva sociocultural y, por cierto, tomando como un elemento central el concepto de literacidad ${ }^{6}$, desde la mirada que Cassany lo ha acuñado.

Respecto de las diversas formas de lectura que conviven en la actualidad, Chartier ha sido claro en establecer que "...conviene tener en cuenta que las formas producen sentido y que un texto está revestido de un significado y un estatuto inéditos cuando cambian los soportes que le proponen a la lectura" (1998:12). No es lo mismo leer Conversación en la catedral en la edición de Planeta a la que se encuentra disponible en el tablet. Mucho más allá de eso, la consideración de que hoy se crea una infinidad de textos en la red, los cuales tienen una circulación y una relación con el autor o autores en las cuales se pierde la misma noción de autor, en la que los lectores intervienen el texto de variadas formas. En esa perspectiva, la discusión sobre qué títulos deben ofrecer las bibliotecas públicas tiene otro acento, pues nadie ha preguntado cuántas son las conexiones de red que están a disposición de los usuarios de las bibliotecas públicas, qué calidad posee dicha conexión y quién la opera.

En efecto, hoy existe y circula una profusión de textos en diversos soportes: podemos leer textos impresos, otros digitales y multimediales, vale decir, nuestra forma de leer en la actualidad es heterogénea, pero la preferencia que poseemos sobre la materialidad de los textos que mayoritariamente leemos está cruzada por nuestra edad y cuán alfabetos digitales somos. Sin embargo, aquello no obsta para establecer que los lectores actuales poseen un modo de lectura denominada simultánea.

La materialidad que crecientemente va predominando es la de los textos digitales y multimediales o multimodales, en definitiva, un texto que conjuga no solo unidades lingüísticas, vocablos y oraciones con sentido completo, sino que también gráficos, dibujos, viñetas, emoticones, sonidos, etc., y que habitualmente está enlazado con otros textos, lo que denominamos "hipertexto", es decir, que los hipervínculos que entrelazan un texto con otro es una propuesta de trayecto formulada por el autor; ciertamente, el lector es libre de aceptarlo o inventar otro. Ello implica que nuestro modo de leer se ha habituado a textos breves y en distinto formatos, por el cual un texto nos lleva a otros en derroteros en los que el lector es quien - en la mayoría de los casos- construye dicho trayecto. Cuando hablo de textos breves me refiero a las unidades lingüísticas con sentido completo, que se presentan generalmente en párrafos de 10 a 20 líneas entre gráficos o dibujos, u otros símbolos; elementos todos que constituyen un texto multimodal y que no necesariamente es digital. Si observamos los libros impresos para niños y jóvenes, siguen el mismo patrón; incluso los textos multimediales, como películas o documentales, poseen una extensión más breve que antaño.

En este contexto, hay que hacerse la pregunta: ¿cómo se forman los lectores en la actualidad? Mayoritariamente, los niños que ingresan a la escuela ya tiene sus primeros acercamientos a los textos impresos, sin embargo, es en la escuela donde comienzan a

6. El concepto de literacidad considera todos los conocimientos, habilidades y actitudes, así como valores derivados del uso generalizado, histórico, individual y social del código escrito. Para una mayor profundización de este concepto véase a D. Cassany, en particular el texto Tras las líneas. 
relacionarse sistemáticamente con ellos. En contrapartida con los textos digitales o multimediales, con los que se relacionan cotidianamente y al ingresar a la escuela, esta los aleja de aquellos, dado que no pueden usar el WI, el celular, la tablet, etc. En nuestras aulas —en particular, las públicas —, las clases siguen siendo frontales, con exposiciones del profesor y niños escribiendo en cuadernos con lápices... pero, ies la escuela la que forma lectores? Numerosos autores plantean que la escuela, en la actualidad, no forma lectores (Hebrard, 2000; Lerner, 2001; Petit, 2009), más bien desfavorece la formación de estos.

Es así que, cuando se está pensando en los lectores, lo que se tienen en mente son aquellos lectores de principio del siglo XX o, en el mejor de los casos, los lectores de los años 60, vale decir, se está recurriendo a la imagen de un lector de libros de tapa dura y buena encuadernación (el de principios de siglo), o al joven de pelo largo que anda con ediciones de bolsillo de novelas del boom (el lector de los 60), y nótese que no hago referencia a ninguna imagen de lectora, aunque, según todas las estadísticas, las mujeres son las que más leen. En la mayoría de los casos, cuando se habla de los lectores se hace referencia a un concepto abstracto, que proviene de una cultura libresca que ya está en retirada o, por lo menos, sitiada y no se considera al "lector empírico" (Bombini, 2009). Esta categorización intenta de alguna manera visibilizar al lector actual, aquel que no lee en la textualidad impresa, sino más bien sus lecturas surgen del soporte digital muy arraigado en la cultura juvenil.

Sobre el lector empírico no tenemos claro cómo definir qué tipo de lector es, pues sus gustos o textos preferidos están fuera del canon y, por cierto, de las aulas escolares. Así, por ejemplo, hoy en día se incorpora en las aulas escolares el análisis del comics. Ciertamente, es el ingreso de una expresión de la cultura de masas a las aulas, pero de los años 50 o 60; hoy son las redes, que operan con otros formatos, las que constituyen la lectura masiva entre los más jóvenes.

En este punto creo que es necesario recurrir a lo que Cassany ha referido en diversos artículos, respecto de las representaciones sobre la lectura y que, por cierto, determinan en buena medida cómo se forman los lectores y a quiénes consideramos lectores. Las tres representaciones a las que hago mención se refieren a la lingüística, la psicolingüística y la sociocultural.

La concepción lingüística concibe que la lectura debe recuperar el sentido semántico de un texto y, por lo tanto, este surge de la suma del significado de sus vocablos y oraciones. Así, entonces, el significado es único y estable, permanece fijo en el tiempo con independencia de los lectores y su contexto. Esta concepción se observa demasiado reiterada en nuestras aulas escolares en los primeros niveles de enseñanza básica, donde los niños dan sus primeros pasos en la lectura formal, en las que se pone el acento en las

7. Uno de los componentes centrales de la Reforma Educacional chilena de los 90 fue estimular y desarrollar las nuevas tecnologías de información y comunicación. Es así que en 1992 se creó el Programa Enlaces para llevar a cabo ese cometido. Según sus propios datos, al año 2013, 9149 establecimientos cumplen con los estándares de infraestructura digital de los 12.116 que existen en Chile. Lo que implica un $75 \%$ de cobertura en todos los niveles: parvulario, básico y medio de las escuelas públicas. 
unidades léxicas, en su pronunciación e incluso en la velocidad lectora como una forma de comprensión del texto. Las evaluaciones tanto de aulas como estandarizadas apelan a la comprensión de los textos en forma lineal o, dicho de mejor manera, los textos con un significado posible — el del profesor o profesora_-, sin considerar la mirada de estos pequeños lectores que han nacido en un mundo letrado $y$, por tanto, tienen una comprensión de este acorde a su edad y a su propio contexto.

Por su parte, la concepción psicolingüística plantea que el sentido del texto se construye en una relación dialógica entre el lector y el texto, por ende, que el significado se construye a partir de esa relación, lo que implica que el texto puede tener múltiples significados. Lectores diferentes entienden el mismo texto de diversas maneras, cruzados por su contexto y experiencias vitales. Lo que implica que cada lector debe desarrollar habilidades cognitivas implicadas en el acto de comprensión del texto, tales como aportar conocimientos previos, hacer inferencias, formular hipótesis, verificarlas o reformularlas. Esta mirada está más presente en los niveles de enseñanza media y últimos años de enseñanza básica, aun cuando no es lo predominante. ${ }^{8}$

La concepción sociocultural, a su vez, reconoce y adscribe lo que aporta la psicolingüística, pero además incorpora algunos elementos o distinciones, tales como que el conocimiento previo tiene un origen social y modelado por la lengua nativa (pensamos a través de la lengua); el discurso siempre refleja un punto de vista, una visión de mundo, se habla desde un lugar. Discurso, autor y lector son parte de una tríada compleja, constituida a partir de normas y tradiciones fijadas por la comunidad de la cual surgen.

Leer no es solo un proceso donde intervienen unidades lingüísticas y capacidades mentales, es una práctica cultural inserta en una comunidad específica que posee historia, tradición, hábitos y determinadas prácticas comunicativas. Esta perspectiva se ve muy poco en las actuales aulas de nuestro país y, cuando se ve, es por una iniciativa del profesor o profesora, porque él o ella es un lector crítico que reflexiona sobre su quehacer.

En la dimensión de la realidad de las aulas es que quiero establecer la distinción respecto de la didáctica de la lectura y la didáctica de la literatura, pues no es solo un tecnicismo la diferenciación, sino que ambas, a mi juicio, apuntan a cosas distintas. Tenerlo claro implica diseñar o planificar clases en función de aquello que pueda ser más efectivo para contribuir a formar lectores, así como también para reflexionar sobre lo que debe incluir un plan de formación de profesores, quienes tendrán la responsabilidad de enseñar a leer a los niños y jóvenes de nuestro país.

En la práctica de formar lectores una primera responsabilidad la tienen quienes enseñamos a leer, pero si nosotros no tenemos la pasión ni la práctica de la lectura es

8. Véase el artículo Flórez, T., "Lengua castellana y comunicación en la educación secundaria", en Revista Latinoamericana de Estudios Educativos, Vol. XLI, N 1-2, México, 2011, págs. 61-102. Se exponen allí los resultados de un estudio descriptivo desarrollado por el Programa de Educación Continua para el Magisterio de la Universidad de Chile, que resume la experiencia de observación de clases llevada a cabo por el Programa, entre 2004 y 2008, en las aulas de diversos establecimientos de enseñanza media en la clase de Lengua Castellana y Comunicación. 
complejo no solo formarla, sino que fomentarla, pues, al contrario de lo que se pudiera pensar, al interior del aula una de las actividades que se hace más a menudo es leer, el punto es la profundidad de esa lectura, la conformación del aula como una comunidad lectora y el modelamiento que el propio profesorado va ejerciendo entre los niños y jóvenes en relación a ella.

La didáctica de la lectura se enmarca, desde mi perspectiva, en el ámbito de formar lectores que posean la competencia de leer críticamente un texto construyendo su propia versión de este. Un papel importante juega aquí la selección de los textos a trabajar, pues se utilizan textos de diversa funcionalidad, como por ejemplo informativos, narrativos, expositivos, etc., y la materialidad de estos. Por su parte, la didáctica de la literatura considera la base de su reflexión la enseñanza y aprendizaje de textos que se establecen desde la ficcionalidad, ${ }^{9}$ la caracterización de la escritura como una modalidad discursiva en sí, y esto constituye un corpus que no solo conforma los textos escritos (escrito o impreso), sino híbridos que combinan sonidos, imágenes, movimientos, etc., y que, ciertamente, poseen una dimensión estética; su objeto de estudio - entendido de esta manera- está imbricado con el conjunto de prácticas sociales que utilizan la escritura ficcional o escritura literaria como sistema simbólico, y la tecnología en contextos específicos y con fines específicos.

En la sala de clases se combinan permanentemente ambas, la didáctica de la literatura ayuda muchísimo a formar un lector crítico desde pequeño a partir de los cuentos infantiles, pero también desde las películas. Ejemplo emblemático puede ser el análisis de una película como Shrek, por la tensión que instala en la conformación de estereotipos muy arraigados en el imaginario no solo infantil. En esa perspectiva, sigo la postura de Bombini, quien planteó dinamizar el concepto de literatura proponiendo otras alternativas en relación a la literatura escolar ligadas a la cultura adolescente, y romper con la hegemonía que pone el acento en la historia de la literatura y en la lectura canónica. ¡Hay que leer a los clásicos desde otro modo! A modo de ejemplo, incluir la película Troya en la clase de literatura, en un diálogo con el texto clásico en el cual está basado. ${ }^{10}$

La creación de comunidades lectoras al interior del aula implica construir prácticas de interpretación que construyen un encuentro entre el "mundo del texto" y el "mundo del lector", esto implica tener en cuenta las creencias, gustos, juicios y prejuicios de quienes leen, así como también de ir en contra de la lectura puramente semántica de los textos y tener en cuenta que las formas producen sentido. Ejemplo paradigmático de esto es analizar lo que sucede en la sala de clases cuando se escuchan algunos poemas de Mauricio Redolés.

Una de las condiciones básicas para comenzar a conformar estas comunidades lectoras es erradicar el concepto de un sentido único posible en la interpretación de un texto y acoger la diversidad de sentidos que construyen cada uno de los lectores,

9. En estricto rigor, toda escritura es representación. En esa perspectiva, la ficción estaría presente en todo texto.

10. Véase Bombini, G., La trama de los textos. Problemas de la enseñanza de la literatura, Buenos Aires: Lugar Editorial, $2^{\mathrm{a}}$ ed., 2005. 
desarrollando una discusión sobre esos múltiples sentidos posibles, entendiendo que los individuos interpretan a partir de su lugar en el mundo y en los contextos en los que se desenvuelven. También, recuperar la figura del lector, lo que implica tener especial cuidado en no caer en simplificaciones que matan los textos y en la falsa dicotomía discurso literario opaco y discurso didáctico transparente: "Poco se ha trabajado sobre la opacidad del discurso en el aula y sobre las ventajas pedagógicas de sostener esa opacidad, de ser deliberadamente ambiguos y construir desde ese discurso una posición de enseñantes" (Bombini, 2009).

Sostener la opacidad implica ir al fondo de la esencia de la literatura; todo texto literario nos sorprende como un hecho de lenguaje que lo trae al primer plano, produciendo placer o disgusto estético y un sentido. Todo ello, ciertamente, se produce con distinta intensidad en cada uno de los individuos que lee un texto - y esa es la esencia de la literatura-, lo que estremece a uno deja frío al otro. Los textos son ambiguos porque a algunos les susurran y a otros les gritan cosas muy distintas.

Respecto del modelamiento al que me referí en párrafos anteriores, tiene que ver con el rol del profesor o profesora como mediador y facilitador; estos deben llevar al estudiante a su nivel de desarrollo potencial "determinado por el aprendizaje con la colaboración de un compañero más capaz o con la guía de un adulto" (Vigotski, 1995:121), produciendo una relación cognitiva importante entre los estudiantes y sus experiencias de lectura. En este sentido, la importancia de la mediación docente en los procesos de lectura de los estudiantes en el aula exige un profundo compromiso de transformarse en "cómplice", "guía", "facilitador" de aprendizajes significativos, creando un clima en el que los alumnos y alumnas se sientan acompañados en su lectura, comprendidos en sus gustos y necesidades, lo que en buenas cuentas significa considerarlo como un otro válido.

El término acuñado por Bombini, "lector empírico", es clave a la hora de considerar las nuevas formas de leer y, por ende, en pensar los diseños de clases acordes con el lector empírico. Si consideramos que el soporte mayoritario que hoy funciona es el digital, ¿deberíamos enseñar a leer en la pantalla? No tengo respuesta para ese interrogante, sin embargo, hoy encontramos muchos juegos didácticos digitales que desarrollan funciones básicas para comenzar la lectura —Abra palabra, por ejemplo—, así como también varias editoriales han comenzado a trabajar en forma paralela con ambos soportes, como Editorial Santillana ${ }^{11}$, que en su línea de textos escolares tiene su soporte digital La casa del saber, a la que solo se ingresa con un código individual que está impreso en el libro. En esta propuesta editorial lo que está implícito es la transición por la que está atravesando la lectura, de una lectura extensiva (se accede y lee muchos textos, pero con poca profundidad y comprensión cabal de ellos) a una lectura simultanea (textos en distintos formatos, pero mayoritariamente digitales o en red, los que ocupan animaciones, voces en off, etc.); sin embargo, poco sabemos del nivel de compresión de ellos.

11. Al amparo del encuentro entre educación y nuevas tecnologías, se desarrolla muy vigorosamente una industria educacional con todas las implicancias que pueda tener esta sociedad. Muchos han reflexionado sobre ello y así lo plantea José Joaquín Bruner en su texto Educación e Internet, ¿la próxima revolución? 
Un estudio de caso sobre alfabetización ${ }^{12}$ en $2^{\circ}$ nivel de transición de educación parvularia, a través de estrategias basadas en el uso de TICs, realizado en diversos establecimientos de la Región Metropolitana ha develado que el cómo enseñar a leer no pasa por establecer lineamientos claros en el uso de TICs como un medio que favorece el proceso de enseñanza-aprendizaje, debido a que los recursos tecnológicos del aula han sido "incorporados", como quien compra un televisor o un computador para el hogar, pero creyendo que, por tal hecho, mejorarán los resultados del aprendizaje. El problema radica en que los establecimientos y algunos docentes piensan que con "incorporar tecnología" es suficiente, y no como una integración curricular de TICs. Esto implica un cambio radical en la sala de clases pero, por sobre todo, en la formación de profesores en general.

En efecto, para la conformación de sujetos con práctica lectora se requiere conocer a ese "lector empírico", acompañarlo en sus lecturas, escuchar sus propuestas de lectura y discutirlas animadamente, solo así estaremos creando lectores para el siglo XXI.

Uno de los factores centrales para elevar la calidad de la educación dice relación con la formación de profesores. Ciertamente, el Estado debe mejorar las condiciones de base para que las universidades mejoren sus programas de formación pedagógica, pero las universidades deben hacer cambios de fondo reales y efectivos en dichos programas, en los que se consideren los desafíos de la sociedad en la cual los y las estudiantes de hoy se desenvolverán en su vida adulta. Una de ellas es considerar como competencia esencial que el futuro profesor (a) sea un lector(a) crítico.

\section{BIBLIOGRAFÍA}

Bombini, G., La trama de los textos. Problemas de la enseñanza de la literatura, Buenos Aires: Lugar Editorial, 2005, 135 pp.

Cassany, D., Tras las líneas. Sobre la lectura contemporánea, Barcelona: Anagrama, 2006, 352 pp.

Cavallo, G. y Chartier, R., Historia de la lectura en el mundo occidental, Madrid: Taurus, 1998, 584 pp.

Vigotsky, L., Lenguaje y pensamiento, Barcelona: Paidós, 1995, 237 pp.

12. Devia S., "Estudio de caso: Alfabetización en segundo nivel de transición de educación parvularia a través de estrategias basadas en TICs", tesis para optar al grado de Magíster en Educación, mención Informática, Universidad de Chile, Facultad de Ciencias Sociales, 2013, 350 pp. 